\title{
Amputees of Hand and Level of Their Involvement in Crimes
}

\author{
Surender Pratap Singh ${ }^{1}$ \\ Fmr. Dy. Superintendent (Finger Print)/Finger Print Expert \\ ${ }^{1}$ Central Finger Print Bureau, National Crime Records Bureau, Government of India \\ Ministry of Home Affairs, Mahipalpur, New Delhi, India
}

\begin{abstract}
A person with missing hand is considered disabled, and becomes a subject of compassion by individuals or group with intact limbs. Such amputees are generally seen as incapable of accomplishing difficult tasks, sometimes even routine chores. Linking such person/s with a crime, is often claimed by his family and friends, as mischievous endeavour by the law enforcement agencies to fix an innocent, for closure of a case. Nevertheless, there has been history of persons with missing hand/s, committing heinous crimes including murders and dacoities. One-armed woman bandit Putli Bai is one such glaring example, she racked havoc for many years, by committing numerous dacoities and murders in areas of Central India, from 1955, until she was killed in a police raid on $23^{\text {rd }}$ January 1958. Furthermore, Sir George Mackenzie of Rofehaugh, in his book, The Laws and Customs of Scotland in Matters Criminal, published in 1699, cites Alex Benedict Paree, the famous French Chirurgeon (surgeon) and others making mention of persons who ate, drank, played at cards and other games with their toes and one of that stole, robbed, murdered with them (toes), and suffered dead for doing so. About $15 \%$ of the world's population lives with some form of disability, of whom $2-4 \%$ experience significant difficulties in functioning. In our study out of 20000 (twenty thousand) ten-digit finger print record slips of the convicts scrutinized, only 50 persons with either of their hands amputated / missing, could be traced. In percentile terms it was only $0.25 \%$ of total 20000 convicts considered for study. In other words, the level of participation of the disabled (here amputees of hand) was only 0.125 per 10000 (ten thousand) convicts. The objective of this paper was to find out the level of participation of Indian amputees of hand, in different types of crimes, using finger print record slips of the convicted persons. Out of 50 disabled convicts traced, 26 had their Left-hand (LH) missing, while 24 were Right-hand (RH) Amputees. In comparison to the RH amputees, the involvement of $\mathrm{LH}$ amputees in crimes was higher, signifying that in order to attempt any of the errands, dominant hand plays a major role. $46 \%$ convicts with amputated Right-hand, had participated in crimes under Indian Penal Code (IPC), while those with-left hand amputation, were involved in $60 \%$ of such crimes. The law enforcement agencies may take a cue from the findings of this research, and avoid exempting people from the list of suspects, merely on the basis of a physical condition. The numbers may be minuscule, but the amputees can commit crimes, akin to persons with intact limbs.
\end{abstract}

Keywords: Amputation of hand, finger print record slips, conviction details, demographic data. Personal Identification Number (PIN).

\section{Classification of disability}

\section{INTRODUCTION}

The International Classification of Functioning disability and Health (ICF) [1], advanced the understanding and measurement of disability. It was developed through a long process involving academics, clinicians, and - importantly persons with disabilities [2]. The ICF emphasizes environmental factors in creating disability, which is the main difference between this new classification and the previous International Classification of Impairments, Disabilities, and Handicaps (ICIDH). In the ICF, problems with human functioning are categorized in three interconnected areas:

- impairments are problems in body function or alterations in body structure - for example, paralysis or blindness;

- activity limitations are difficulties in executing activities - for example, walking or eating;

- participation restrictions are problems with involvement in any area of life - for example, facing discrimination in employment or transportation.

Disability refers to difficulties encountered in any or all three areas of functioning. The ICF can also be used to understand and measure the positive aspects of functioning such as body functions, activities, participation and environmental facilitation. The ICF adopts neutral language and does not distinguish between the type and cause of disability - for instance, between "physical" and "mental" health. "Health conditions" are diseases, injuries, and disorders, while "impairments" are specific decrements in body functions and structures, often identified as symptoms or signs of health conditions [3].

What is amputation?

Amputation is the removal of a limb by Trauma, medical illness, or surgery. As a surgical measure, it is used to control pain or a disease process in the affected limb, such as malignancy or gangrene. In some cases, it is carried out on individuals as a preventive surgery for such problems. A special case is that of congenital amputation, a congenital disorder, where fetal limbs have been cut off by constrictive bands. In some countries, amputation of the hands, feet or other body parts is or was used as a form of punishment for people who committed crimes [4], [5], [6].

Guidelines for consideration of disabilities of hand for compensation in Denmark

The determination of compensation for deformity/disability (in Denmark) is always based on the latest guiding disability table from the National Board of Industrial Injuries (NBII) [7]. 
Table-1: Part of extract of the disability table from NBII, Denmark

\begin{tabular}{|l|l|l|l|}
\hline S. No. & Part of the Body & Right Hand (RH) & Left Hand (LH) \\
\hline 1 & Loss of arm (whole arm) & $70 \%$ & $65 \%$ \\
\hline 2 & Loss of hand & $60 \%$ & $55 \%$ \\
\hline
\end{tabular}

Like India, in Denmark too more value is given to the right hand of their population, amputation of right-hand, in comparison to the left-hand, is considered a bigger loss. As per the guiding disability table of the National Board of Industrial Injuries (NBII), the loss of right-hand results in $60 \%$ disability, while the missing left hand would be considered as $55 \%$ disability, for the purpose of compensation.

\section{Number of disabled in the world population}

About $15 \%$ of the world's population lives with some form of disability, of whom $2-4 \%$ experience significant difficulties in functioning. The global disability prevalence is higher than previous WHO estimates, which date from the 1970 s and suggested a figure of around $10 \%$. This global estimate for disability is on the rise due to population ageing and the rapid spread of chronic diseases, as well as improvements in the methodologies used to measure disability [8].

\section{Population of disabled persons in India}

As per the Census 2011, In India out of the $121 \mathrm{Cr}^{*}$ population, $2.68 \mathrm{Cr}$ persons are 'disabled' which is $2.21 \%$ of the total population. Among the disabled population $56 \%$ $(1.5 \mathrm{Cr})$ are males and $44 \%(1.18 \mathrm{Cr})$ are females. In the total population, the male and female population is $51 \%$ and $49 \%$ respectively. Majority (69\%) of the disabled population resided in rural areas $(1.86 \mathrm{Cr}$ disabled persons in rural areas and $0.81 \mathrm{Cr}$ in urban areas). In the case of total population also, $69 \%$ are from rural areas while the remaining $31 \%$ resided in urban areas [9].

Table-2: Total population versus number of disabled persons in India (2011)

\begin{tabular}{|c|c|c|c|c|c|}
\hline \multicolumn{4}{|c|}{ Total population of India in 2011} & Number of disabled persons in India 2011 \\
\hline Persons & Males & Females & Persons & Males & Females \\
\hline $121.08 \mathrm{Cr} *$ & $62.32 \mathrm{Cr}$ & $58.76 \mathrm{Cr}$ & $2.68 \mathrm{Cr}$ & $15 . \mathrm{Cr}$ & $1.18 \mathrm{Cr}$ \\
\hline
\end{tabular}

\section{Crime against persons with disabilities}

The rate of serious violent crime for persons with disabilities (12.7 per 1,000) was more than three times the rate for persons without disabilities $(3.9$ per 1,000) in 2010 to 2014 . The age group with the highest victimization rate was the 16- through 19-years-old group followed by 12 - through 15 years old group with no statistically significant difference between the groups. The age group with the lowest victimization rate was the 65 and older group for persons with and without disabilities. For both males and females in 2010 through 2014, the rate of violent victimization was higher for persons with disabilities than for those without disabilities [10]. The above data clearly shows that the disabled persons are more vulnerable to crimes against them, but in this study, emphasis would be to understand the level of involvement of the disabled persons as perpetrators of crimes.

\section{Disabled persons \& crime}

Executing a criminal act, such as theft, robbery, murder, grievous hurt, drug peddling, arms smuggling etc., is challenging even for an individual with fully functional hands, and to do a felonious act efficiently with only one hand, is generally beyond one's discernment. But perception and reality may not be same always, there has been history of crimes committed by amputees of hand. The notorious Putli Bai is a glaring example, the one-armed petite woman dacoit, played havoc from 1955 to 1958 in many areas of Central part of India. She was wanted for a number of murders, dacoities \& other serious crimes, and was finally got killed in a police raid on $23^{\text {rd }}$ January 1958 , but not before a fierce gun battle between her gang and the police. She was proficient in handling firearms with one arm/hand. In an earlier police encounter, she had received a bullet wound in her lower left arm, and got it covertly amputated to avoid infection or gangrene [11].

Sir George Mackenzie of Rofehaugh (1636-1691) in his book, The Laws and Customs of Scotland in Matters Criminal, printed at Edinburgh by Andrew Anderson and Heirs printer to most excellent Majesty, DOM in 1699, in chapter on Mutilation and Dememberation, has written, "We will find that some man born without hands, have performed the like actions with toes, as the hand is in use to do, he cites Alex Benedict Paree, the famous French chirurgeon (surgeon) and others making mention of persons who ate, drank, played at cards and other games with their toes, and one of that stole, robbed, murdered with them, and suffered dead for doing so." [12].

\section{Age and Crime}

Patterns of behaviour, including violence, change over the course of a person's life. The period of adolescence and young adulthood is a time when violence, as well as other types of behaviours, are often given heightened expression [13]. A study on the development of delinquency in Cambridge, England, found that one-third of young males who had been convicted of offences involving violence before the age of 20 years were convicted again between the ages of 21 and 40 years, compared with only $8 \%$ of those not 
convicted for violent offences during their teenage years [14].

\section{Age of the disabled and crime}

The percentage of disabled persons is highest in the age group 10-19 years followed by age group 20-29 years for both the male and female disabled persons [15]. In any study involving disabled persons, like amputees of hand, in crimes, certain physiological aspects should also be given due deliberation; age, health and muscle strength of such persons would also matter in their ability to perform felonious activities. Younger amputees, with good muscle mass of the available limbs, would be better capable of committing crimes. Natural age-related muscle loss, may not let the ageing amputees to sustain optimum levels of proficiency for activities requiring better precision and strength.

Age-related muscle loss, called sarcopenia, is a natural part of aging. After age 30, you begin to lose as much as $3 \%$ to $5 \%$ per decade. Most men will lose about $30 \%$ of their muscle mass during their lifetimes. Less muscle means greater weakness and less mobility, both of which may increase your risk of falls and fractures. A 2015 report, from the American Society for Bone and Mineral Research found that people with sarcopenia had 2.3 times the risk of having a low-trauma fracture from a fall, such as a broken hip, collar bone, leg, arm, or wrist [16].

\section{Handedness and Crime}

Handedness is the dominance of one hand over the other, or the unequal distribution of fine motor skills between the left and right hands. There are five main types of handedness, which are Right-handedness (or dextrality), Lefthandedness (or sinistrality), Ambidexterity (where people are able to perform any task equally well with either hand), Ambilevous or Ambisinistrous (where people are equally clumsy with both hands), and Mixed-handedness or crossdominance (where people tend to perform different tasks better with different hands). It is far from clear that our dominant right-handedness or our predominantly left-sided heart (or any other aspect of laterality in humans) owes anything at all to this molecular-level or atomic-level chirality, although such a link has been hypothesized [17].

As per estimates, when compared to the world's populations, $70-90 \%$ of them are Right-handed, while 10-20\% are Lefthanded, next to them are the mixed handed with 5-6\% count, and the rest 1-4\% probably would be Ambidextrous \& Ambisinistrous together. It is pretty clear from the estimates, and previous studies that majority of the world population is of those who use Right-hand as their dominant hand, while the Left-handed persons are comparatively less. And, when the dominant hand is lost or amputated, it becomes much harder for an individual to perform even routines activities. In this study out of 50 disabled convicts traced, 26 had their Left-hand (LH) missing, while 24 were Right-hand (RH) Amputees. In comparison to the $\mathrm{RH}$ amputees, the involvement of $\mathrm{LH}$ amputees in crimes was higher, suggesting that in order to attempt any of the errands, probably dominant hand plays a major role. Although, it cannot be claimed with $100 \%$ surety, whether the concept of dominant-hand, had played any role in level of participation of RH or LH amputees in crimes, as the slips studied here did not have any mention of convict's handedness. Yet, as the number of right-handed people in India is more (in comparison to the people residing in the western world), the chances of right-hand dominance in case of the convicts studied, may prevail.

\section{OBJECTIVE}

To study, and analyse the level of participation of Indian amputees of hand in crimes.

\section{MATERIALS AND METHOD \\ Methodology: Data and data collection \\ The Data: Finger print record slips of the convicts}

The finger print record slips stored in the Bureaux of India, carry finger impressions, demographic information, and conviction details of the convicts, duly endorsed by authorized government officer. The method of using finger print record slips as an authentic tool for this criminological research, relies on the conviction details of individuals, after they were found guilty, in the light of acceptable evidence, and were thus punished for their crime/s by the honourable courts of law. Furthermore, the methodology has been successfully tried, and tested many times by the author since 2004, when he first used it, to publish a research paper on the topic- A study: Involvement of women in violent crimes [18].

This study was carried out at the Central Finger Print Bureau (CFPB), New Delhi, which is the national repository of finger print record slips of convicted persons, and stores them as per the list of crimes given in the 'Schedule of Offences' of its work manual i.e. CFPB Manual. The CFPB has a database of over 1.2 million 10-digit finger print slips of the convicted persons on record, both in the form of hard copies, as well as electronic or digital version on its Automated Finger Print Identification System (AFIS). Hard copies are stored in rectangular steel trays in the pigeon-hole cabinets. There are 72 trays in each cabinet, and approximately 300-400 finger print record slips are stacked in each of these trays. The FP slips are stored serially in the trays, on the basis of unique 11-digit unique ID Number, which is called Personal Identification Number (PIN). The small white rectangular self-adhesive sticker having Personal Identification Number, also carry a unique bar code to identify the PIN, and the FP record slip, on which it is fixed or pasted.

\section{Process of data collection}

(i) 10-digit finger print record slips of convicted persons with missing / amputated hand filed in the record section of the Central Finger Print Bureau (CFPB), provided as a source of raw data.

(ii) A total of 20000 (twenty thousand only) 10-digit finger print record slips of the convicts were manually scrutinized for research. Two trays were randomly picked from different pigeon-hole cabinets, each slip of the tray was carefully examined, and those slips showing amputation of hand (i.e. slips with missing row of 5-rolled finger 
impressions of either of the two hands, plain impressions of fingers of only one hand, and impression of only one thumb) were picked-up. Out of the total records inspected, there were only 50 (fifty) finger print slips of the convicts bearing details of missing/ amputated hands. In CFPB, finger print slips of amputees too are stored with other slips; there are no separate trays or cabinets for storage of such slips. Thus, the process was cumbersome and time consuming.

(iii) The relevant information, about the amputated hand (left or right etc.), demographic, and conviction details from the selected 50 ten-digit finger print record slips of the convicts, were taken down on the data collection sheet, for further analysis.

\section{Period of study}

The study was completed in six months, from June to November 2018.

\section{RESULT}

Out of the total of 20000 ten-digit finger print record slips scrutinized, only 50 convicts with either of their hands amputated / missing, were found. In percentile terms it was only $0.25 \%$ of total slips scrutinized. In other words, the level of participation of the disabled (here amputees of hand) individuals in crimes, was only 0.125 per 10000 (ten thousand only) convicts with both of the hands intact. This also highlights that the contribution of amputees of hand, in crimes is miniscule, as compared to able-handed convicts.

Table-3: \% participation of amputees of hand in crimes

\begin{tabular}{|l|l|l|}
\hline Total No. of slips scrutinized & No. of slips of amputees of hand found & $\begin{array}{l}\% \text { participation of amputees out of total } \\
\text { slips scrutinized } \\
50 / 20000 x 100\end{array}$ \\
\hline 20000 & 50 & $0.25 \%$ \\
\hline
\end{tabular}

The selected slips for study were categorized into those of the Right-hand (RH) amputees and the others belonging to the Left hand (LH) amputees. Out of the total of 50 of such convicts traced, there were 26 Left-hand (LH) amputees, while the remaining 24 had their Right-hands (RH) missing.

Table-4: Number and \% of convicts with amputation of Right-hand and Left-hand

\begin{tabular}{|l|c|c|c|}
\hline \multicolumn{4}{|c|}{ Number and \% of convicts with amputation of RH and LH (i.e. RH/50 \& LH/50) } \\
\hline \multirow{2}{*}{ RH Amputees } & \multicolumn{2}{c|}{ LH Amputees } & \multicolumn{2}{c|}{$\%$ LH Amputees } \\
\hline 24 & $48 \%$ & 26 & $52 \%$ \\
\hline
\end{tabular}

Pie Chart-1: \% involvement of convicts with amputation of Right-hand \& Left-hand

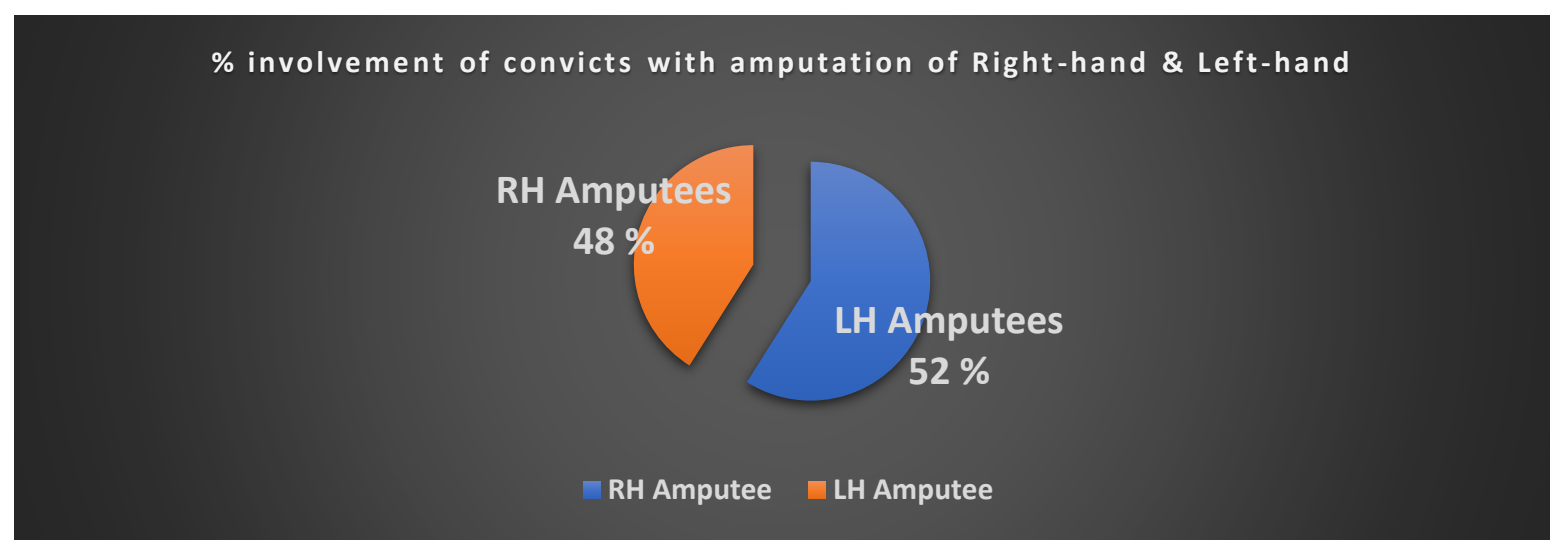

Table-5: \% Involvement of amputees of Right-hand in different categories of crimes

\begin{tabular}{|l|l|l|l|l|l|l|}
\hline $\begin{array}{l}\text { \% of RH } \\
\text { amputees in } \\
\text { crimes } \\
\text { (out of 24) }\end{array}$ & IPC & Arms Act & Excise Act & NDPS Act & POCSO Act & SLLs \\
\cline { 2 - 7 } & $46 \%$ & $4 \%$ & $39 \%$ & $7 \%$ & $2 \%$ & $2 \%$ \\
\hline
\end{tabular}


Pie Chart-2: \% Involvement of amputees of Right-hand in different categories of crimes

\% Involvement of amputees of Right-hand in different categories of crimes

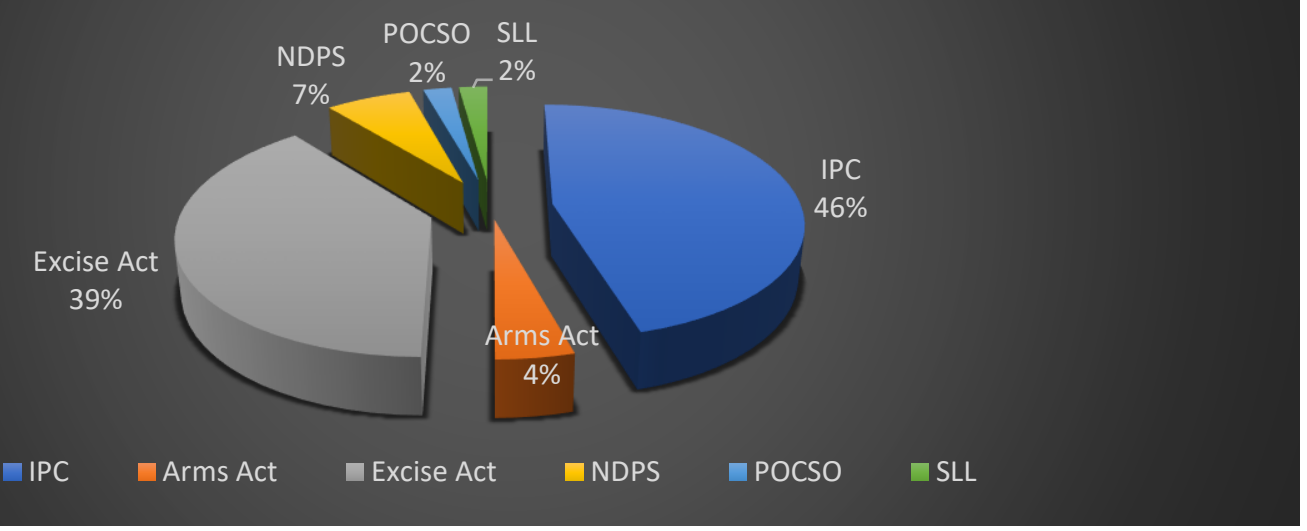

Table-6: \% Involvement of amputees of Left- hand in different categories of crimes

\begin{tabular}{|l|l|l|l|l|l|}
\hline $\begin{array}{l}\text { \% of LH amputees in } \\
\text { crimes } \\
\text { (out of 26) }\end{array}$ & IPC & Arms Act & Excise Act & NDPS Act & SLLs \\
\cline { 2 - 6 } & $60 \%$ & $6 \%$ & $26 \%$ & $6 \%$ & $3 \%$ \\
\hline
\end{tabular}

Pie Chart-3: \% Involvement of convicts with Left- hand amputation in different crimes

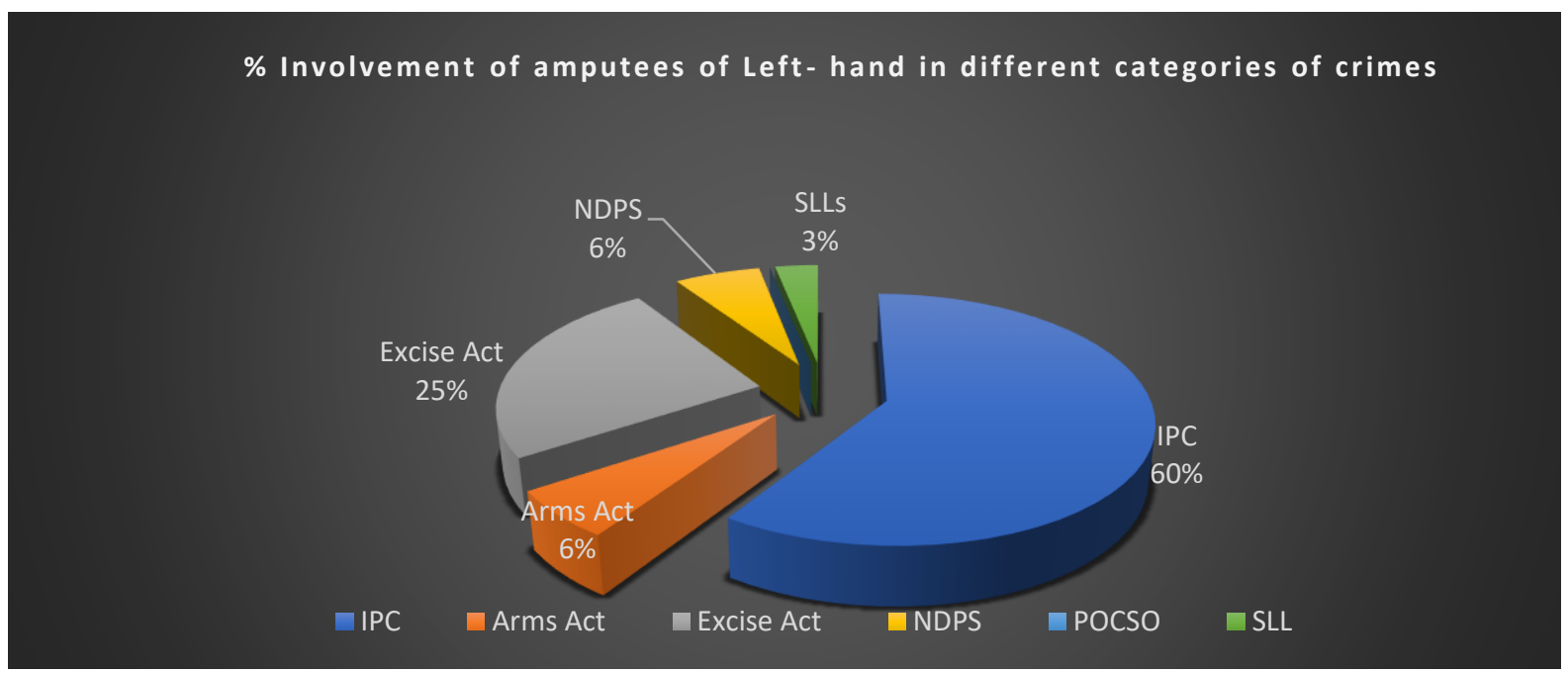

\section{ANALYSIS OF RESULT}

1. In this study convicts with amputation of one hand were found to be involved in various categories of crimes like Indian Penal Code, Arms Act, Excise Act, and State \& Local Laws (SLLs). They had their participation in, theft, dacoity, extortion, forgery, causing hurt/grievous hurt, attempt to suicide, feticide, and murder.

2. Participation of Amputees of Right-hand (RH) in different types (falling in various Acts and Laws) of crimes was $48 \%$ (24 participants out of 50).

3. Participation of Amputees of Left-hand ( $\mathrm{LH})$ in different types (falling in various Acts and Laws) of crimes was $52 \%$ (26 participants out of 50 ).
4. The amputees of Right-hand (RH) had $46 \%$ participation in IPC crimes (46\% of 24 numbers of such convicts)

5. The amputees of Left-hand (LH), had $60 \%$ involvement in IPC crimes $(60 \%$ of 26 numbers of such convicts)

6. The involvement of convicts with amputation of Right-hand (or the left hand intact), in crimes falling under Indian Penal Code (IPC) Crimes was less.

7. The involvement of convicts with amputation of Left-hand (or the right hand intact), in crimes falling under Indian Penal Code (IPC) Crimes was more. 
The Right-hand (RH) in India is considered as dominant hand, if the same is amputated, it may adversely affect a person's ability to perform various activities, including committing crimes.

\section{CONCLUSION}

- The level of participation of the amputees of one hand was 0.25 in 20000 (twenty thousand), or 0.125 per 10000 (ten thousand) convicts.

- The amputees of hand studied here, participated in variety of crimes like theft, forgery, extortion, hurt/grievous hurt, feticide, and even murder.

- Although, it cannot be claimed with $100 \%$ surety, whether the concept of dominant-hand was valid in this study, and had played any role in the level of participation of Right-hand or Left-hand amputees in crimes, as none of the slips scrutinized, had mention of convict's handedness. Nevertheless, by means of the higher number of right-handed people in India, the chances of right-hand dominance in case of the convicts studied, might prevail.

\section{REFERENCES}

[1] The International Classification of Functioning disability and Health (ICF). Geneva, World Health Organization, 2001.

[2] Bickenbach JE, Chatterji S, Badley EM, Ustün TB. Models of disablement, universalism and the international classification of impairments, disabilities and handicaps. Social science \& medicine (1982), 1999,48:1173-1187. doi:10.1016/ S02779536(98)00441-9 PMID:10220018

[3] WHO, World Report on Disabilities, Chapter 1 Understanding disability, Pg. 5 WHO Press, Geneva, Switzerland, 2011 available at: https://www.who.int/publications/i/item/worldreport-on-disability Accessed 15.07.2020

[4] Whitelaw WA (March 2005). "Proceedings of the 14th Annual History of Medicine Days". Research Gate.

[5] Kocharkarn W (Summer 2000). "Traumatic amputation of the penis" (PDF). Brazilian Journal of Urology. 26: 385-389 - via Official Journal of the Brazilian Society of Urology.

[6] Peters R (2005). Crime and Punishment in Islamic Law: Theory and Practice from the Sixteenth to the Twenty-First Century. Cambridge University Press. ISBN 9780521792264. https://www.who.int/disabilities/world_report/2011/report/en/ Accessed: 10.07.2020

[7] IDA Forisking, IDA's Insurance Group, Disability Table, Here's an overview of the disability table from National Board of Industrial Injuries, Copenhagen, V Danmark. Available at: https://idaforsikring.dk/en/disability-table-mentabeller Accessed: 11.05.2020.

[8] WHO, World Report on Disabilities, WHO Press, Geneva, Switzerland, 2011 available at: https://www.who.int/disabilities/world_report/2011/report/en/ Accessed: 10.07.2020

[9] Census of India 2011, Registrar General \& Census Commissioner, Ministry of Home Affairs, Government of India, Available at http://censusindia.gov.in/2011common/census_2011.html, Accessed: 08.05.2020.

[10] Audrey, Demmitt, RN, Dealing with Crime or Domestic Violence as a person with Disability, Crime Against Persons with Disabilities (2009-2014): The Facts, Vision Aware, Copyright 2020 American Printing House for the Blind. Available at: https://visionaware.org/emotionalsupport/dealing-with-crime-or-domestic-violence-as-a-personwith-a-disability/crime-against-persons-with-disabilities/ Accessed: 11.07.2020.
[11] Singh, S.P., (2020) Putli Bai - India's First Bandit Queen, LinkedIn, July 2020, Pg. $1 \&$ 2. Available at https://www.linkedin.com/in/s-p-singh-88149043/detail/recentactivity/ Accessed: 15.07.2020

[12] Mackenzie, Sir George, Mutilation and Dememberation, The Laws and Customs of Scotland in Matters Criminal, Printed at Edinburgh by Andrew Anderson and Heirs printer to most excellent Majesty, Edinburgh, 1699, Pg. 21, para 62, line 1-6.

[13] Dahlberg LL, Potter LB. Youth violence: developmental pathways and prevention challenges. American Journal of Preventive Medicine, 2001, 20(1S):3-14

[14] Farrington DP. Predicting adult official and self-reported violence. In: Pinard GF, Pagani L, eds. Clinical assessment of dangerousness: empirical contributions. Cambridge, Cambridge University Press, 2001:66-88

[15] Harvard Men's Health Watch, Preserve your muscle mass, Declining muscle mass is part of aging, but that does not mean you are helpless to stop it. February, 2016 Available at: https://www.health.harvard.edu/staying-healthy/preserve-yourmuscle-mass Accessed: 09 Jul 2020.

[16] Mont, Daniel. (2004) Disability Employment Policy, Disability and Development Team, The World Bank, 2004: p7, Available

https://digitalcommons.ilr.cornell.edu/cgi/viewcontent.cgi?artic le $=1433 \&$ context $=$ gladnetcollect, Accessed: 08.05.2020

[17] Mastin, Luke. 2012, Right Left Right Wrong? An Investigation of Handedness-Some Facts, Myths, Truths, Opinions, and Research Available at: https://www.rightleftrightwrong.com/what.html Accessed: 15.07.2020.

[18] Singh, S.P. (2004) 'A study: Involvement of women in violent crimes', The Indian Police Journal, New Delhi, India, Jan-March 2004, L1(1): 100-1006. 